\title{
Teachers' Disciplinary Boundedness in the Implementation of Integrated Computational Modeling in Physics
}

\author{
Rebecca Vieyra $^{1}$ (D) . Joshua Himmelsbach ${ }^{2,3}$
}

Accepted: 8 September 2021 / Published online: 27 September 2021

(c) The Author(s) 2021

\begin{abstract}
This study explored teachers' conceptualizations of integrated computational modeling in secondary physics by exposing twelve experienced physics teachers to programming and then analyzing interview responses. Responses revealed that teachers fell along a spectrum of disciplinary boundary-stretching mentalities. This paper presents a preliminary conceptual framework for exploring both horizontal (interdisciplinary) and vertical (intradisciplinary) boundary stretching, as well as for identifying bounded mentalities as teachers consider integration. Horizontal boundary stretchers envisioned opportunities to use computational modeling to shift their curriculum or pedagogical approaches in physics to help students enhance skills underlying multiple fields, while vertical boundary stretchers considered how computing might allow students to explore physics concepts more deeply. Teachers with more boundary-stretching indicators at the outset of an integrated curriculum development workshop were more likely to persist in the implementation of computational modeling-integrated materials in their physics classrooms than those who expressed more bounded thinking. These findings emphasize the importance of considering teachers' perceptions about how their own science discipline is connected to similar fields and provide implications about how to identify potential adopters of innovative teaching approaches.
\end{abstract}

Keywords Physics $\cdot$ Computing $\cdot$ Computational modeling $\cdot$ Integration

\section{Introduction}

Many advancements in science rely upon researchers' interactions with complex computational models. The Framework for K-12 Science Education (NRC, 2011) and the Next Generation Science Standards (NGSS) (NGSS Lead States, 2013) have challenged U.S. science educators to re-envision their disciplines with the integration of forward-looking computational practices. For example, NGSS Science and Engineering Practice \#5, "using mathematics and computational thinking," potentially advances students' abilities to use new technologies to "make meaning from the large

Rebecca Vieyra

rvieyra@aapt.org; rebecca.elizabeth.vieyra@gmail.com

Joshua Himmelsbach

jlh@umd.edu; himmelsbach@cua.edu

1 American Association of Physics Teachers, One Physics Ellipse, 5th Floor, College Park, MD 20740, USA

2 College of Education, Department of Teaching, Learning, Policy, and Leadership, University of Maryland-College Park, College Park, MD 20742, USA

3 Department of Mathematics, Catholic University of America, 620 Michigan Ave. NE, Washington, DC 20064, USA amounts of data they produce, [which] is becoming a defining feature of scientific work in the 21st century" (Weintrop et al., 2016, p. 135). The wide adoption of the NGSS and the advancement of CSforAll (CSforAll, n.d.) have led to an explosion of national initiatives and policy dialogue associated with the integration of science with computing (K-12 Computer Science Framework, 2017; NASEM, 2010; and NSF, 2019).

This study examines computational thinking (CT), the fundamental conceptual skills underlying computing (Wing, 2006) in a particular context: computational modeling in physics. Computational modeling (CM) emphasizes the computational representation of relationships within a system, most notably through code, programming, and the creation and use of simulations. The integration of CM in physics, in this case, refers to the use of computational models through programming to represent physical relationships.

Our exploration of CM occurs in the context of a physics education research project funded by $100 \mathrm{Kin} 10$ and the National Science Foundation's STEM+C program (AAPT, n.d.). In our project's first year, we worked with physics teachers who previously participated in at least 3 weeks of 
training in Modeling Instruction ${ }^{\mathrm{TM}}$ (MI) (Wells et al., 1995) and who were familiar with a physics first approach that mandates that all freshmen take physics. We chose physics first because they include greater gender, racial, and ethnic diversity than more advanced physics electives (White \& Tesfaye, 2011, 2014; White \& Tyler, 2015). We chose MI because more than 14,000 teachers across the U.S.A. have been trained in this reformed teaching approach (American Modeling Teachers Association, n.d.) that emphasizes discipline-specific socioconstructivist learning theories and the creation, testing, and application of mental models. MI teachers represent a population of educators who are eager to adopt and refine discipline-specific, evidence-based approaches in their classrooms, and who are likely to be early adopters of reform.

In 2016, we recruited 12 experienced MI physics teachers to participate in a workshop that introduced them to programming through Bootstrap:Algebra (Bootstrap, 2021). Bootstrap:Algebra is an approach for teaching introductory CM based on How to Design Programs (Felleisen et al., 2001) that aims to improve students' understanding of algebraic functions. Bootstrap was developed for secondary students and uses the Pyret programming language created by Brown University's introductory computer science faculty to help students with no prior programming experience overcome common obstacles (see pyret.org for a full comparison with other language tools).

During the workshop's first week, we exposed the physics teachers to Bootstrap pedagogy and tools to design their own programs and simulations. Teachers participated in a whole group discussion about Weintrop et al. (2016) taxonomy for CT for mathematics and science classrooms, as well as the NGSS Science and Engineering Practices relating to CT. This conversation was guided with support from Dr. Kathi Fisler, a member of the K-12 Computer Science Framework (2017) author panel. Recognizing the lack of consensus around the definition of computational thinking at the time, she helped the leadership team express to participants our hope was that they would use Bootstrap and Pyret to serve as jumping-off points to consider what integration might look like in their physics contexts.

After 1 week learning to program, we asked teachers to spend 2 weeks developing integrated curricular materials for teaching physics using the MI approach. Rather than provide explicit guidelines to teachers about the possible goals or objectives of such an integrated curriculum, such as possible goals identified by Orban and Teeling-Smith (2020), we encouraged teachers to first consider for themselves if or how integrating $\mathrm{CM}$ might support their own goals for students, whatever they might be.

Our research explores how these teachers conceptualized the integration of $\mathrm{CM}$ into their physics instruction after 1 week of $\mathrm{CM}$ exposure. We also investigate whether there was a relationship between the way teachers think about CM-physics integration and their likelihood of implementing CM in their classroom, using the materials they codeveloped with each other during the program. Our study provides insight into how other science teachers might react to their first encounter with programming, specifically, and to integrated approaches, generally.

\section{Theory of Learning}

Our research on $\mathrm{CM}$ - and the MI context in which we study it-employs a theory of learning that is founded on the construction, revision, and application of conceptual models (Hestenes, 1987; Johnson-Laird, 1983; Piaget, 1964). Conceptual models are mental constructs composed of interrelated understandings and beliefs, including conceptual, procedural, and affective aspects. The construction of these models reflects the way learners organize and interpret how they perceive the external world. To reveal their conceptual models to others, learners communicate their thinking through representations such as words, algebraic expressions, graphs, and drawings. MI is well-aligned with modern perspectives that learning is dependent upon engaging learners' prior knowledge, deep conceptual understanding, the use of explicit metacognitive practices (NRC, 2000), as well as emotional, social, and cultural contexts (NASEM, 2018). Using a physics-centric approach, the theory of learning undergirding MI corresponds well with the discipline-based education research initiatives that suggest that general pedagogy alone is insufficient for good teaching (NRC, 2012).

While MI makes use of probeware and graphical analysis tools on computers, our project aimed to also incorporate programming to create simulations representing the physical world and/or to generate data for analytical and predictive purposes. CM through programming adds computer code and programs to the learners' representational toolbox. In MI classrooms, learners deliberately self-assess their mental constructs through Socratic dialogue and the use of whiteboards to display their thinking. Our project included code among these visual representations that were used in these discussion sessions.

In considering our teachers as (integrated) physics learners in our study, we adopt MI's socioconstructivist, model-focused theory of learning for our analysis. We do so because all our research participants use MI instruction in their own classrooms, and they typically used the language and the lens of models and modeling when they reflected upon their own conceptualizations of the disciplines they teach. We expected that our research participants, as experienced physics teachers, had a strong sense of what is taught in introductory secondary physics courses. In applying this theory of learning to our research, we expected that teachers' 
prior conceptions of their discipline influenced how they perceived the integration of $\mathrm{CM}$ in their physics classes, as well as their motivation to implement integrated materials.

\section{Literature Review}

The integration of multiple disciplines within the sciences has revealed numerous sources of tension for teachers. Berlin (1991) and Berlin and Lee $(2003,2005)$ reported an explosion of interest in math and science integration in the 1990s. However, the overall benefits of integration have not always been clear. Following Czerniak et al. (1999) concerns about integrated instruction's effectiveness, Hurley (2001) review found quantitative evidence for improved learning outcomes from integration, but reported that teachers found integration to take extra effort. A review by Pang and Good (2000) asserted that despite enthusiasm from pre-service teachers about integration, "teachers who do not have underlying foundational knowledge of other disciplines can facilitate, at most, superficial connections among disciplines" (p. 77). In studying the habits of science teachers specifically, Wang et al. (2011) found that science teachers struggled to integrate technology and science content, instead focusing their efforts on underlying problem-solving skills. Despite this tendency, multiple U.S. initiatives are calling for science teachers to integrate transdisciplinary content more explicitly, including computing (NRC, 2011; NAE \& NRC, 2014).

Mueller et al. (2008) and Langbeheim et al. (2020) are among the few researchers studying science teachers' attitudes about the integration of computing into their disciplines. Mueller et al. (2008) identified that K-12 teachers' levels of computer integration in non-computing subjects were dependent upon the teacher's previous "positive outcomes with computers; teacher's comfort with computers; specific beliefs related to the use of computers as an instructional tool; and the teacher's own use of computers at home and at school" (p. 1532). Notable, however, is that Mueller et al.'s study focused more on teachers' attitudes toward the computer as an object, rather than the computer as a pedagogical tool. More specific to CM, Langbeheim et al. (2020) reported that prior experience with $\mathrm{CM}$ and programming can lead to higher initial self-efficacy scores for teachers to integrate programming into their teaching of 9th grade physics, but that all teachers, regardless of prior experience, can see significant self-efficacy gains.

Limited research has focused on specific affordances and limitations that teachers perceive and encounter regarding the integration of CT in their professional development and later classroom instruction. Weintrop et al. (2016) explored how math and science teachers naturally teach CT, inferring from teachers' activities what they prioritize. Computer scientists that have influenced science education by advocating for computing in science include DiSessa (2001), as well as leaders behind initiatives such as Code.org (n.d.) and the CSTA (2017). University-level introductory physics also contributed to research on the utility of computational integration into coursework (Caballero, 2011; Caballero et al., 2012, 2014; Chabay \& Sherwood, 2008, 2015; Chonacky \& Winch, 2008; Cook, 2008; Esquembre, 2007; Lunk, 2012; McIntyre et al., 2008; Niedderere et al., 1991; Obsniuk et al., 2015; PICUP, n.d.; Sherer et al., 2000; Sherin et al., 1993; Sherin, 2001; Spencer, 2005; Timberlake \& Hasbun, 2008; Weatherford, 2011).

Of these studies, none explicitly focused on how teachers understand the disciplines of physics and CM and the ways in which they overlap, or how they apply those understandings as they consider instructional shifts. We are unaware of any studies that have looked at what elements of computing or CM teachers adopt as part of physics as an evolving discipline. For example, we anticipate that teachers who understand the role of computational physics might see computing not as a separate discipline but as a tool of their physics practice. This example stands in contrast to the physics teacher who might think about computing as a supplementary skill from the computer science discipline to which they bridge when necessary. We also expect that how teachers think about the nature of the disciplines they are trying to integrate might affect the motivation they feel to integrate and how they intend to do so.

\section{Data and Methods}

\section{Research Questions}

Because we want to help physics teachers co-create and adopt integrated teaching strategies, it is critical to engage teacher voice to lead the conversation surrounding integration. Teacher-led initiatives are particularly important at the K-12 level to help increase teachers' self-efficacy and willingness to innovate through integration (Kelley et al., 2020). Teachers are primary implementers of educational reform, and we believe it is necessary to hear from teachers their perspective about how the integration of $\mathrm{CM}$ shifts their view of how they would teach physics, and, by association, impact wide-scale curriculum and instruction.

To understand teachers' experiences, we were curious about how secondary physics teachers conceptualize CM integration into physics. Do teachers look for opportunities to integrate computing into the foundation of their instruction, or do they view it as a supplement? What affordances and drawbacks do they see with integration? Further, we wanted to know if the way teachers thought about integration might influence their uptake of the approach. Our analysis of the data was guided by the following questions: How do 
secondary physics teachers conceptualize the integration of CM into physics? How do secondary physics teachers' conceptualizations of the integration of CM into physics relate to their implementation of integrated materials?

\section{Conceptual Framework and Methodological Approach}

We define teachers' conceptualizations as the way they envision how content and skills from physics and computing can be taught and learned together, as well as the benefits and advantages that integration can afford. We embrace a reflexive (Burawoy, 1998) research approach influenced by Erickson (1986) that acknowledges the importance of researcher immersion into subjects' experiences to understand what is essential in the system we aim to study. The original goals of the project were to look at teachers' instructional changes and students' academic gains. However, a few years into the project, we realized that we needed to look deeper into teachers' perceptions of integration to understand the mechanisms influencing teachers' adoption of the $\mathrm{CM}$ integration. As a result, we reject the structured, pre-planned interventions and proscribed measurement techniques advocated by Yin (2009).

In our interviews with teachers, we teased apart the essential elements of their insights relevant to $\mathrm{CM}$ in physics. We discerned how teachers perceived the similarities and differences between CM-integrated physics and non-computational forms of modeling in physics (i.e., the discipline that they teach). We listened for how teachers perceived the similarities and differences in the act of teaching CM-integrated physics and non-computational forms of modeling in physics (i.e., the pedagogy that they use).

\section{Research Participants and Context}

We introduced 12 experienced secondary teachers to Pyret, a text-based language, to learn programming skills with the Bootstrap:Algebra curriculum and pedagogy (Fig. 1). Teachers hailed from the New England region of the U.S.A., and all had previously completed a 3-week MI workshop. All participants had implemented the MI approach in their classrooms for multiple years, and several had experience leading MI workshops for other teachers.
Fig. 1 Pyret interface showing sample student code for a computational model of a drag car race

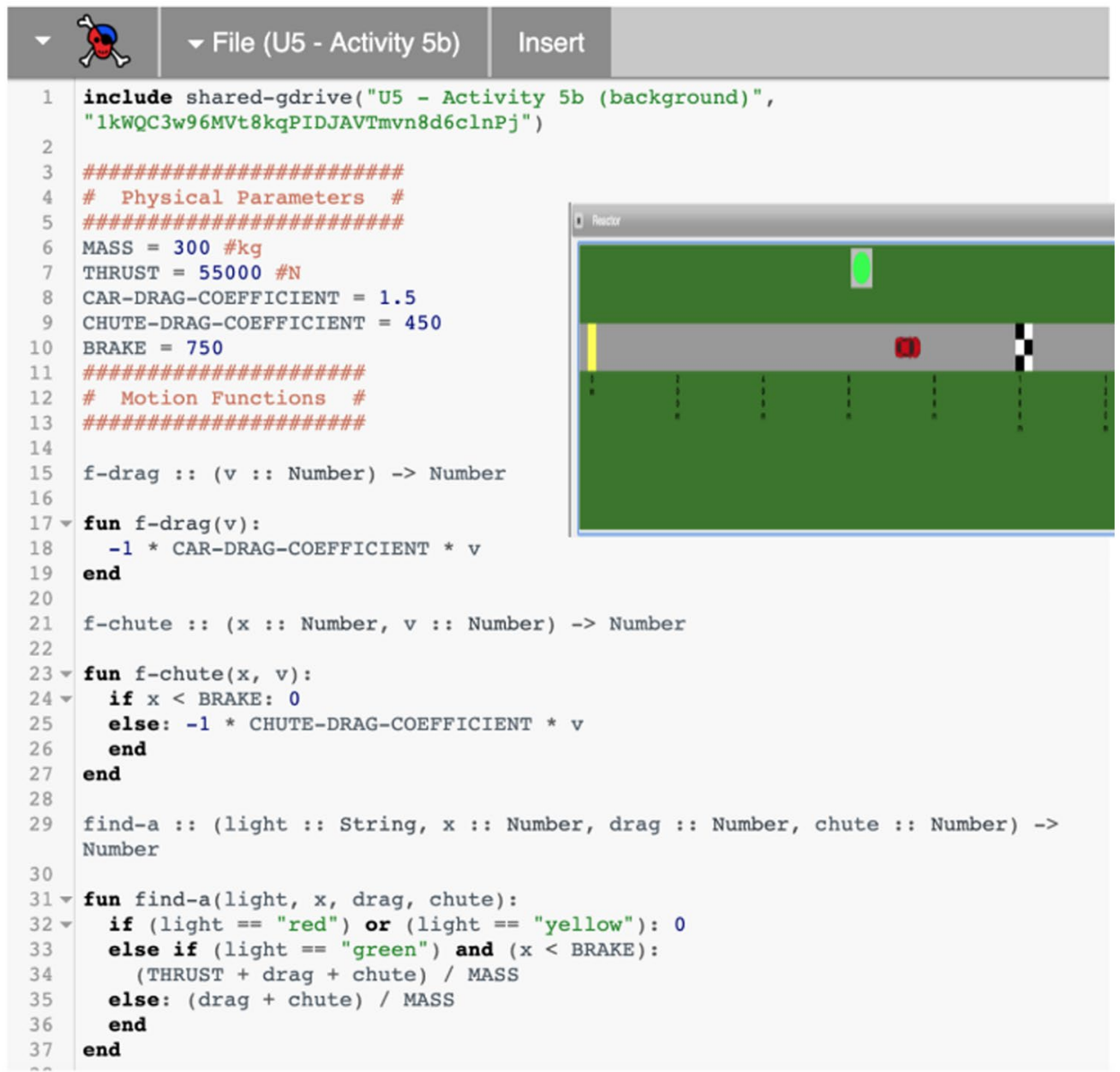


The first week of our 3-week workshop consisted of instruction in programming by the Bootstrap:Algebra team. The programming experience introduced teachers to programming concepts, including numbers, strings, images, multi-input/multi-type functions, Boolean logic, events, and visual design, as well as the design recipe, a pedagogical tool that helps students to build and test their programs. They learned how to apply these concepts to create interactive simulations (such as a constant velocity car or launching rocket) and data models (tables, graphs, best fit trend lines). The goal of the workshop was to provide teachers with enough programming skills to see the possibilities for designing integrated curriculum for physics contexts.

After 1 week of learning to program, we asked participants how they thought about CM integration in their own classes. These semi-structured interviews allowed teachers to consider how they might integrate what they learned in the previous week with their teaching of physics. Over the following 2 weeks, teachers put that vision into practice as they developed integrated curricular materials. Throughout those weeks, teachers struggled with how to prioritize ideas within physics and computing given limitations of time and student (and teacher) ability.

To provide a practical illustration of how the participants integrated computation into physics in the workshop, consider a teacher's instruction about constant velocity. Traditional teachers might introduce the formula speed $=$ distance/time and expect students to apply the equation to word problems. In contrast, a MI teacher might help students build their model for motion by providing a motorized, constant velocity car, a meter stick, and a stopwatch, and encouraging students to create a graph and associated algebraic model that corresponds to the best-fit line. A MI teacher who integrates $\mathrm{CM}$ might use the same motorized car experience with students. However, instead of providing students with a stopwatch to measure elapsed time, the teacher might provide a metronome and ask students to consider the position of the car at each "tick," the distance traveled from one tick to the next, and the total number of ticks.

With this slight modification of using the metronome instead of a stopwatch, students might think about change in position as a function of position moment-to-moment, mimicking computational processes that are agnostic of elapsed time. Paired with more typical instruction that makes use of Cartesian graphs with time axes to derive relationships from those graphs, the students who used the metronome might also be encouraged to create an algorithmic model. The program below is an example of this kind of time-agnostic (and position-dependent) function for a car that is moving $2 \mathrm{~cm}$ per implicit computational "tick."

\section{fun next-x}

\section{current- $\mathrm{x}+2 \# \mathrm{~cm}$}

end

This time-independent representation corresponds to the time-based equation that would traditionally be derived from a graph $\left(x_{f}=v_{\text {ave }}{ }^{*} t+x_{i}\right)$. Throughout the study of mechanics, this new representation can be used both in written form and to create and use simulations that complement other ways of expressing physical relationships (Fig. 2).

The above example illustrates a way to think about and represent constant velocity motion that is novel for most teachers and students. It can also be adapted to represent accelerated motion, a concept with which students can struggle because of its parabolic time-based relationship. From a programming perspective, these motion representations are the foundation for solving problems or creating simulations that not only display kinematics, but also forces, Newton's laws, and energy transformations—content that makes up

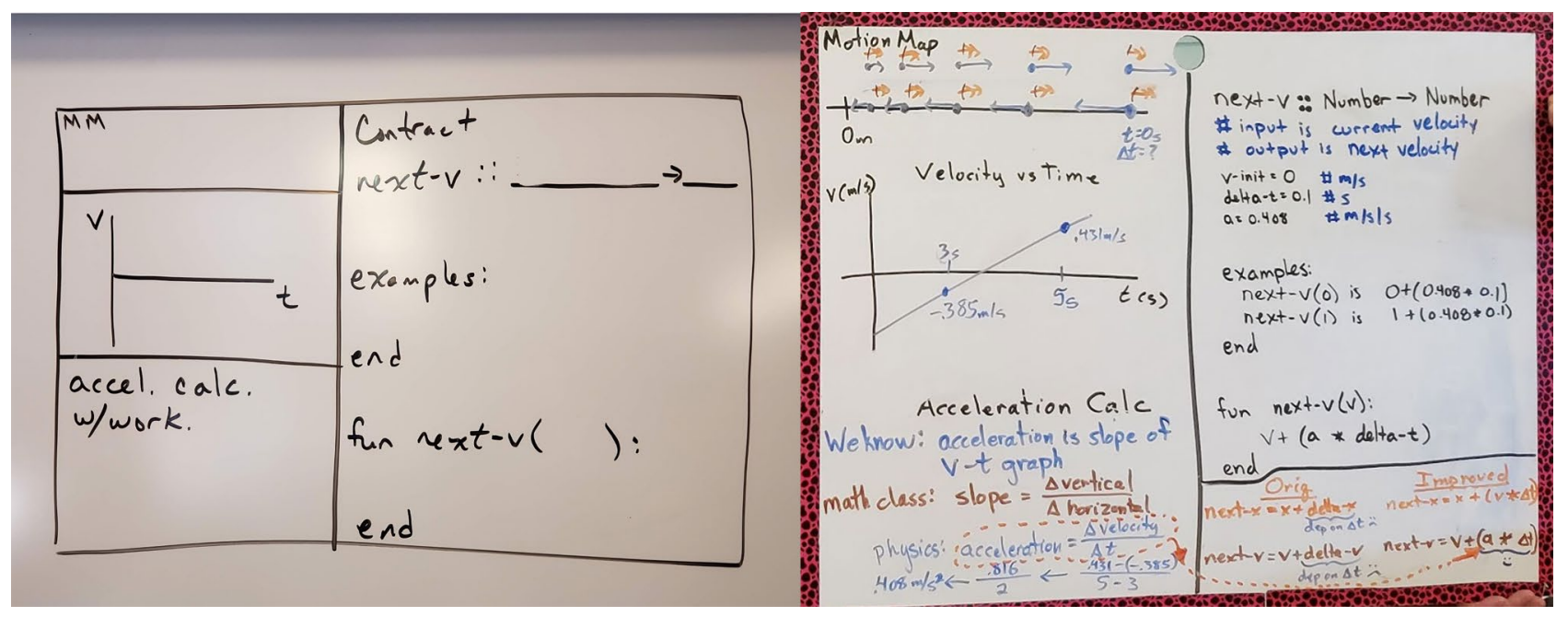

Fig. 2 Blank and filled whiteboards showing corresponding representations of acceleration 
most of the introductory physics curriculum. Teachers regularly referenced the above example and those similar to it in their interviews.

\section{Interview Protocol and Data Coding}

We used a semi-structured protocol to reveal teachers' conceptualizations of integration in the context of their classroom instruction. Interviews took 15-45 min and included the following questions:

- Q1: Can you tell me a few ways that you might use what you learned last week to complement conventional physics instruction?

- Q2: Can you think of any kind of an activity developed by you or someone else that you think is a good example of integrating programming with physics learning?

- Q3: Is there any physics content that you see differently after this workshop - enhancements, contradictions, limitations in understanding?

We transcribed the interviews and looked for trends using a constant comparative process (Glaser, 1965). The initial coding scheme produced four types of codes centered around teachers' expectations about the affordances and drawbacks of integrating $\mathrm{CM}$ into their physics classes. These code categories included statements about how CM integration could present (1) content improvements (improving course content offerings), (2) pedagogy improvements (improving course instruction), (3) computer skills applications (increasing computational skills independent of course focus), and (4) barriers (barriers to integrating programming into the course). However, the frequency of coded statements at this level of granularity was evenly distributed per individual and did not reveal meaningful groupings.

To reformulate the codes, we considered distinctions in the literature. Namely, STEM integration research literature often discusses affordances and challenges concerning how well the integration promotes or inhibits connections among disciplines. For example, literature often describes teachers using integration to emphasize underlying science and engineering practices of related fields, such as problem-solving (Czerniack et al., 1999) and the use of computers as modern tools to solve those problems (Chonacky \& Winch, 2008). In these cases, integration breaks down the silos between the disciplines and prepare students for the modern workforce. Some literature, however, especially in physics education, argues for the opportunity to deepen understandings about physics (Chabay \& Sherwood, 2008), such as using computers to explore phenomena that otherwise would be too difficult to quantify or study in a laboratory. Recognizing that secondary physics teachers work at the interface of generalized pre-university education and the specialization of higher education, we parsed the larger coding categories by looking at the nature of content improvements, pedagogy improvements, computer skills applications, and barriers that teachers referenced.

Ultimately, we developed a rubric that identified key phrases that illustrated the various forms of thinking and noted trends on a person-by-person basis. After independently identifying and coding passages for each individual that were related to boundedness or boundary stretching, we tallied statements in each code category. We scored individuals who displayed only boundedness as 1 (highly bounded), and those who displayed only boundary-stretching as 5 (highly boundary stretching). Individuals who displayed a mix of commentary were scored as 2,3 , or 4 , depending upon the relative frequency and the specificity of the comments. To ensure inter-rater reliability, we discussed score discrepancies until we reached agreement about the nature of each passage. Final independent scores did not differ by more than one point, and the final overall score reported reflects the average of independent scores.

To qualify teachers' long-term implementation of CM in physics, we categorized each teacher based upon whether they implemented the materials over the following academic year by using monthly gatherings to ask for details about implementation frequency, including specific activities and times of year when they were implemented. We made holistic judgment about persistence based upon teachers' selfreports, evidence of efforts to modify or create new shared materials, and engagement within the cohort. We scored implementation over the period of the following year as no persistence (no significant implementation), limited persistence (occasional, opportunistic integration), or persistence (consistent use of materials as-is or with modifications).

\section{Results}

Interviews revealed that teachers had different values and expectations for the integration of computing into physics. Teacher revealed a spectrum of what we call boundary stretching and bounded mentality. Teachers expressed boundary stretching by thinking about enhancements within the content they already taught (vertical boundary stretching), or by embracing new material as an extended component of what they saw as a new part of physics education (horizontal boundary stretching). Boundary-stretching teachers made explicit links to calculus and the importance of $\mathrm{CM}$ in understanding physical relationships and problem-solving. In contrast, teachers with evidence of boundedness were more likely to think about $\mathrm{CM}$ as a supplemental layer to place on top of their existing curriculum for additional practice, but without deepened learning. These teachers emphasized computing as a separate domain, and sometimes held a fragmented view 
of CM ideas (such as placing an over-emphasis on syntax or coding, rather than on programming or modeling). Although teachers with bounded mentalities did not always object to the inclusion of what they saw as other disciplines, they did not embrace the new material as an essential part of physics education or their responsibilities as a physics teacherthese teachers saw themselves more as boundary crossers than boundary stretchers.

We provide the following example data from three participants, Allison, Marcos, and Connor (pseudonyms), to illustrate the range of responses that we received during the interviews.

\section{Example Data}

Allison: Allison was an experienced regular and calculusbased advanced placement physics teacher. In response to Q1, her reaction to her first week of exposure to the programming centered around the discrete moment-to-moment world view of computing, which shares similarities to calculus (but differs significantly from the continuous function models often used in algebra-based physics):

...there's a really good link between calculus [and CM] oddly enough, and, you know...and calculus-based physics. What I consistently find is my kids could take a derivative or take an integral, but they don't understand what a derivative or an integral is. The way that computer science is presenting it is in this discrete way, which is the definition [of integrating or differentiating]. ... [Students] don't realize they're thinking in terms of calculus...

In her continued response to Q1, Allison later referred to how teachers often introduce physical relationships by having students collect data and plot a best-fit line to generalize the relationship. She suggests, however, that this might not be the best pedagogical approach, and that programming might be a gentler way to respond to students' natural tendencies:

...[students] look at episodic reads, instant one to instant two. Kids naturally do that. And, up until this point, we've ignored the fact that that's the natural path for the kids, and we're like, let's do this cumulative[ly], because that's how physics does it. We've covered up their impulse to do it episodically. ...it would require very careful thinking about how to honor students' thinking and allows them to understand continuous functions the way physics does it. So [teaching with $\mathrm{CM}$ ] was slightly less intuitive for me, but with some thought could be very well constructed.

Marcos: Marcos was a younger teacher, having taught regular and algebra-based advanced placement physics for 4 years at a private school. While Marcos' responses echoed many of the themes in Allison's interview, in his response to a question about his intent to use the workshop materials, he explained how teachers might struggle to think about motion using representations other than the traditional time-based algebraic equations:

“...I think there's backlash against [computational modeling] because as teachers and as people trained in physics, we are very married to the idea of time-based equations, but I don't think that's actually the easiest way for a person new to the subject. The idea that these equations aren't the only way, or even the best way. For example, trying to write an equation for a ball bouncing back and forth, using a time-based equation, is a nightmare situation, whereas if you have it position-based, it's very simple. Even just giving students that example of the way that we have to look at most things works really well for some situations, but not as well for others, is something that I try to reinforce in my teaching."

Connor: Connor was also an experienced high school physics teacher who taught regular physics students. He emphasized the value he placed on programming to build simulations, but prioritized the end-product over the process of coding. He questioned the practical possibility of integrating $\mathrm{CM}$ in a way that would promote conceptual development. Responding to Q1, he shared the following:

I would have pre-made simulations that students could manipulate certain variables of. They would have access to the code and explicit instructions to change certain parameters to see how the simulations would respond. After looking at the code, they might be asked to create their own code. I didn't see creating their own code as something I would do in class, just because of time constraints. ... There's definitely some really good simulations made, but at the same time, there's already existing simulations like through PhET and other resources.

Connor felt that the goals of teaching students how to code while also learning physics were divergent, as illustrated by his response to $\mathrm{Q} 2$ :

It's a jumping off point (for integration). That alone isn't much of an integration. I feel like if you're going to teach coding, that's a good place to start. ... Throwing an example beyond constant velocity at a student who doesn't know physics and doesn't understand computer science I think would be really challenging.

\section{Indicators of Horizontal and Vertical Boundary Stretching and Boundedness}

Teacher responses demonstrated that their exposure to programming in the first week of their workshop experience 
stimulated their thinking about the nature of physics teaching, including how they think about its content and pedagogical approach. They also discussed personal and professional tensions related to their ability to integrate.

In the case of Allison, she noted connections among calculus, computing, and physics. We refer to these kinds of statements as evidence for a horizontal boundary-stretching mentality. Without providing explicit examples, Allison saw opportunities for teaching about the nature of coding to help students to improve their conceptual understanding about integrals and their application in mathematics and physics, while also building on students' natural tendencies to think episodically rather than with continuous functions.

Marcos and Allison also both described programming as an opportunity to model relationships within physics, with Marcos specifically identifying the importance of computing in representing non-continuous functions in physics courses. We call these kinds of statements, which focus on deepening understandings within a given discipline, evidence of a vertical boundary-stretching mentality.

In contrast, Connor emphasized the value of the endproduct of the coding experience, namely, to simulate physical relationships rather than to develop models through programming. Most of his responses lacked horizontal or vertical boundary-stretching statements. While he recognized that using simulations is a starting point for the integration of CM into physics, he expressed that programming was likely to bring more obstacles into the classroom than not. These kinds of statements that seemed to focus on barriers between physics and computation were described as a form of boundedness.

We developed text-based indicators for evidence of vertical disciplinary boundary-stretching (Table 1), horizontal disciplinary boundary stretching (Table 2 ), and boundedness (Table 3). In general, the contents of Tables 1 and 2 are associated with expectations about disciplinary affordances, and Table 3 refers to expectations about disciplinary challenges of CM integration into physics. Because this study focuses on teachers' views of CM integration, external contextual limitations, such as administrative pressure to teach traditional content, are not included in the rubric.

Our rubrics discriminated teachers' conceptualizations of the integration of CM in physics. Despite the shared training experience, teachers did not think monolithically about integration. Among boundary-stretchers, some teachers expressed mostly vertical boundary-stretching statements, while others emphasized horizontal boundary stretching. Despite the utility of this differentiation for the purposes of identifying teachers' conceptualizations of integration, we noted from our interactions with teachers across the school year that the actual dimensionality (vertical or horizontal) was likely less important to long-term implementation than the evidence of any kind of boundary stretching.

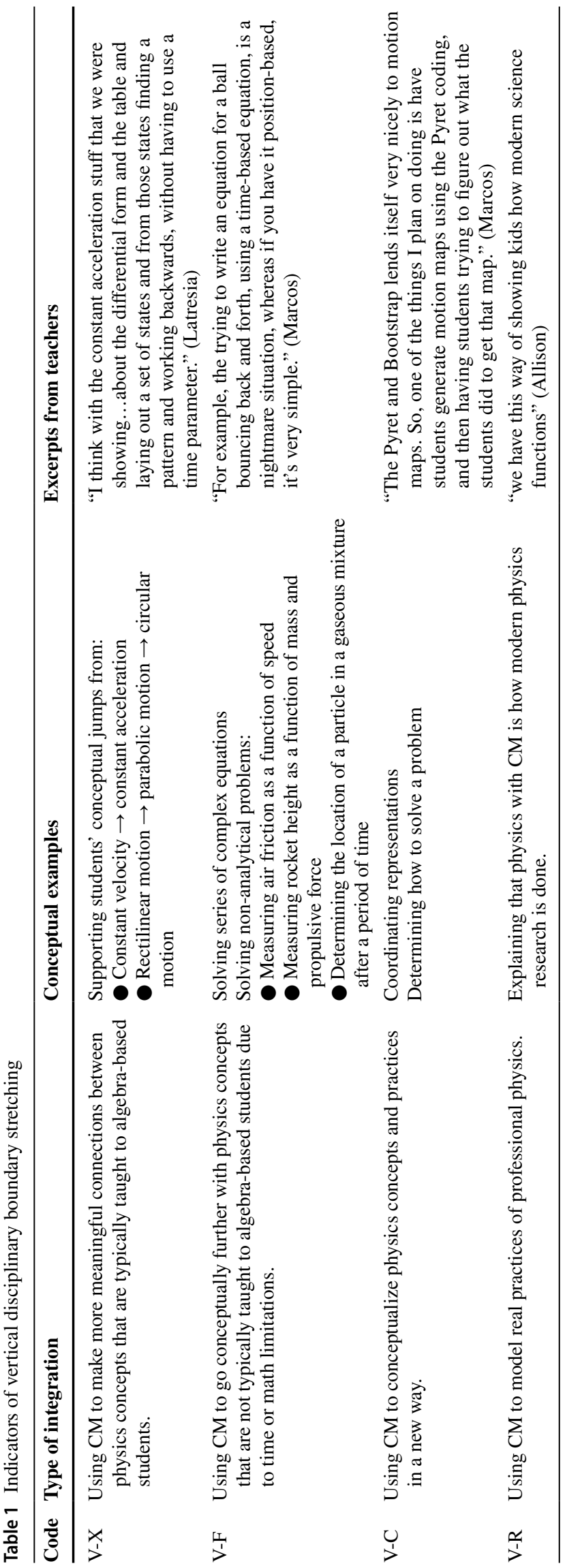


Table 2 Indicators of horizontal disciplinary boundary stretching

\begin{tabular}{|c|c|c|c|}
\hline Code & Type of integration & Conceptual examples & Excerpts from teachers \\
\hline $\mathrm{H}-\mathrm{XC}$ & $\begin{array}{l}\text { Using CM to make explicit, specific } \\
\text { connections between concepts in } \\
\text { physics, computing, and/or math. }\end{array}$ & $\begin{array}{l}\text { Supporting understandings about } \\
\text { the following: } \\
\text { States and systems } \\
\text { Relationships among variables }\end{array}$ & $\begin{array}{l}\text { "I would really like to see them strengthen their own } \\
\text { math confidence and have a better understanding } \\
\text { of functions. They focus too much on } \mathrm{x} \text { as always } \\
\mathrm{x} \text {, and they don't understand what that x represents. } \\
\text { I'm thinking that computer science might help with } \\
\text { that." (Evan) }\end{array}$ \\
\hline $\mathrm{H}-\mathrm{XP}$ & $\begin{array}{l}\text { Using CM to make explicit, specific } \\
\text { connections between practices in } \\
\text { physics, computing, and/or math. }\end{array}$ & $\begin{array}{l}\text { Support the following practices: } \\
\text { Problem-solving } \\
\text { Representing data } \\
\text { Representing relationships. }\end{array}$ & $\begin{array}{l}\text { "I'm attracted to the idea of having students take } \\
\text { data from their own experiments and put it into } \\
\text { tables and then use a function writing process to } \\
\text { fit a curve to it rather than have it, Excel or Plotly } \\
\text { or some other black box, fit a curve to it and } \\
\text { the equation is what it is. So, I'm thinking that } \\
\text { process, of writing their own equation, will help } \\
\text { them understand what equations do and what they } \\
\text { are for and how they get there." (Jake) }\end{array}$ \\
\hline
\end{tabular}

As a result, we chose to holistically score teachers based on the frequency and strength of boundary-stretching versus bounded statements along a single-dimensional scale. These scores are present in Table 4. For example, Connor displayed only boundedness, and both authors scored him as a 1. In contrast, Allison displayed only boundary-stretching, and both authors scored her as a 5. Some individuals, such as Anisa, displayed only boundary-stretching commentary, but provided examples of integration that were vague, leading the authors to score the individual as a 4 . In the case of split scores, as was the case for Andrew and Rogers, the average of the two scores was recorded.

We then used boundedness scores and related them to teachers' implementation outcomes. We define implementation persistence as the use of integrated materials that included Pyret programming - those developed in or following the workshop_-across at least the first full semester of the following academic year. This length of time approximately corresponds to the teaching of mechanics (the study of motion, forces, and energy) in MI physics classrooms, which was the topical focus of the materials developed, as well as the period during which participants were required to attend monthly virtual gatherings to report on implementation. Given the loose structure of the materials that were developed in the workshop and the effort it took teachers to integrate them into their courses' storylines, it was evident to us which teachers were making sincere efforts at implementation. Teachers who persisted were regular contributors to group discussion, shared new materials they had developed, illustrated student work, or sought help. Those who did not persist either did not implement at all or dropped out of monthly gatherings within the first few months of the school year.

Of the seven individuals who scored on the higher end of the boundary-stretching spectrum (a score above 3 ), five demonstrated persistence. Two of these boundary-stretchers, Marcos and Anisa, became what we have called super usersparticipants in our program who, over the course of the following years, created a significant amount of materials, and who advocated publicly through conference presentations and in their teacher communities for wider adoption of integration. Of the two high scorers who did not persist, one attributed the inability to implement to the fact that his colleagues (who did not participate in the workshop) wanted to maintain uniformity across courses. The other became an administrator. The three individuals who scored on the lower end of the boundary-stretching spectrum (a score below 3 ) demonstrated limited or no persistence.

\section{Discussion}

Our findings suggest that teachers who had more boundarystretching mentalities were more likely to implement integrated $\mathrm{CM}$ in physics material. Despite its exploratory nature, our work supports the possibility of a causal connection between science teachers' perceptions of integration and their implementation of it, filling a gap in the literature identified by Stubbs and Myers (2016). These findings suggest that recruiting individuals such as our super users should be one goal of curriculum innovators who need early adopters to seed their efforts. In our research, none of the participants who displayed primarily bounded thinking went on to become super users, even after completing the $\mathrm{CM}$ workshop. As educational researchers and social demands call for changes in the way science is taught, findings from this research demonstrate the importance of teacher perceptions in the development of new materials that push traditional boundaries.

We did not aim to uncover the sources that influenced teachers' conceptualizations of integration and their 
mentalities with regard to it. However, prior findings from Pang and Good (2000) suggest that teachers who only have superficial understandings of the disciplines (physics and/ or computer science) are more likely to display a bounded mentality. While most of our teacher participants scored relatively high on a conceptual pre-assessment of introductory physics (Hestenes et al., 1992), no diagnostic assessment was available at the time to measure teachers' specific abilities with CM. In future studies, we hope to use measures of self-efficacy for $\mathrm{CM}$, which have been used in at least one other study (Langbeheim et al., 2020) as a proxy for computational skills and knowledge that are otherwise challenging to measure in a programming language-agnostic way.

We also anticipate that teachers' sense of CM and disciplinary authenticity (i.e., beliefs about what practicing physicists actually do) might influence teachers' boundedness. Achieving disciplinary authenticity with integration is a challenge for science teachers generally (Kapon et al., 2018) and physics teachers specifically (Watkins et al., 2012). Kapon et al. (2018) identified the various tensions between integrated disciplines: content fidelity, content coverage, language and discursive norms, epistemic structure and standards, and significance. Echoing Pang and Good (2000), teachers struggle to resolve these tensions when they do not have a deep and broad understanding of their own discipline. In studying the integration of physics and the life sciences, Watkins et al. (2012) made the case that integration is not merely about content; the goodness of fit of integrated materials is often about teachers' and students' perceptions about discipline-specific pedagogy, expectations for realworld practice of professional scientists, and the historical traditions of each disciplines' choice and use of tools.

We saw similar themes appear in our research participants' language, including their beliefs about how MI should be done, what should be taught in physics, and what they believed about the work of physicists and computationally literate individuals. Some teachers might be quite familiar with the role of computational physics in modern theoretical research, while others might espouse a more traditional Newtonian or classical view of physics. While some teachers might envision their role as preparing future scientists and engineers, others' goals might focus on achieving general science literacy.

\section{Limitations}

Our conclusions are limited by the small sample size and the fact that we only examined teachers' conceptualizations of integrated CM in their physics classes based on teachers' early expectations of how integration might play out in the classroom after a 1-week exposure to programming. As teachers implemented the integrated approach, they might have uncovered new opportunities and obstacles that shifted 
Table 4 Final scores and implementation outcomes (for boundary-stretching scores, $1=$ highly bounded, and $5=$ highly boundary-stretching)

\begin{tabular}{|c|c|c|}
\hline Participant & $\begin{array}{l}\text { Boundary-stretching } \\
\text { score (average) }\end{array}$ & Implementation outcome during following academic year \\
\hline Gina & 4 & $\begin{array}{l}\text { Limited persistence } \\
\text { Implemented materials at the start of the year only, owing to pressure from colleagues to remain coherent } \\
\text { with curriculum and instruction of other physics teachers in the building. }\end{array}$ \\
\hline Connor & 1 & $\begin{array}{l}\text { No persistence (?) } \\
\text { Did not maintain communication with the program. }\end{array}$ \\
\hline Allison & 5 & $\begin{array}{l}\text { Persistence } \\
\text { Implemented materials as a supplement to existing content. Returned in } 2017 \text { as curriculum developer. }\end{array}$ \\
\hline Andrew & 1.5 & $\begin{array}{l}\text { Limited persistence } \\
\text { Adopted some materials, and returned in } 2017 \text { as curriculum developer, but did not demonstrate evidence } \\
\text { of having implemented in own classroom. }\end{array}$ \\
\hline Evan & 1 & $\begin{array}{l}\text { Limited persistence } \\
\text { Adopted some materials. Expressed that had technology issues, but still implemented as much as possible, } \\
\text { including many of the "unplugged" programming planning activities. Returned in } 2017 \text { as curriculum } \\
\text { developer. }\end{array}$ \\
\hline Latresia & 3.5 & $\begin{array}{l}\text { Persistence } \\
\text { Adopted materials to the best of ability, and created a number of new resources. Returned in } 2017 \text { as } \\
\text { curriculum developer }\end{array}$ \\
\hline Marcos & 5 & $\begin{array}{l}\text { Persistence (super user) } \\
\text { Returned in } 2017 \text { as curriculum developer, then in } 2018 \text { as workshop leader, supported national workshop } \\
\text { presentation, got offered to author a book on differential elementary physics, and created additional } \\
\text { units beyond the materials created by the cohort. }\end{array}$ \\
\hline Anisa & 4 & $\begin{array}{l}\text { Persistence (super user) } \\
\text { Returned in } 2017 \text { as curriculum developer, supported national workshop presentation. However, because not } \\
\text { assigned a physics class, elected to teach drop-in units in colleague's computer science and engineering } \\
\text { classes. Maintained participation in community gatherings for three years. }\end{array}$ \\
\hline Sylvia & 3 & $\begin{array}{l}\text { Persistence (super user) } \\
\text { Returned in } 2017 \text { as curriculum developer, continually active in community ( } 3 \text { years in), regularly provides } \\
\text { feedback on continuous development, expressed interest in being a workshop leader }\end{array}$ \\
\hline Jake & 3 & $\begin{array}{l}\text { No persistence } \\
\text { Did not complete the program. Left after the first week of the workshop. }\end{array}$ \\
\hline Henry & 4 & $\begin{array}{l}\text { Persistence } \\
\text { Returned in } 2017 \text { as curriculum developer }\end{array}$ \\
\hline Rogers & 4.5 & $\begin{array}{l}\text { No persistence } \\
\text { Became an administrator during the following academic year. }\end{array}$ \\
\hline
\end{tabular}

their thinking. Further, given the geographic expanse of participants, we were unable to know, in detail, the quality of implementation. Our data is reliant upon teacher self-report, which we verified in a limited way through observations of teachers' engagement in monthly conversations and the sharing of resources. Future research should explore case studies to better understand the reasons behind teachers' conceptualizations.

\section{Conclusion}

This research achieves two ends. First, the construct of boundary-stretching versus bounded mentalities proved to be a valuable way to characterize teachers' conceptualization of integration. Second, we posit that teachers who displayed a boundary-stretching mentality were more likely to implement the integrated material in their classrooms in the following school year. These findings carry implications for program developers, who may want to strategically recruit likely early-adopters by identifying boundary-stretchers at early stages, as well as for researchers, who can help uncover the sources and possible development of teachers' boundarystretching and boundedness mentalities to better understand persistence in the implementation of integrated material.

Acknowledgements The authors would like to acknowledge contributions to this work from the cohort of 30 middle and high school physics teachers who participated in the workshops, to research collaborators Dr. Colleen Megowan Romanowicz and Dr. Yi Li for helping to design and carry-out the protocol, to collaborator Dr. Fernand Brunschwig of STEMteachers NYC for making these workshops possible through the arrangement and hosting of these workshops, to evaluator Dr. Brandon Helding for his review of this manuscript, and to Dr. Andrew Elby for his assistance with the data analysis. 
Funding This material is based upon work supported by the $100 \mathrm{Kin} 10$ and the National Science Foundation under Grant No. 1640791. Any opinions, findings, and conclusions or recommendations expressed in this material are those of the author(s) and do not necessarily reflect the views of the National Science Foundation.

\section{Declarations}

Ethics Approval All procedures performed in studies involving human participants were in accordance with the ethical standards of the University of Maryland-College Park Institutional Review Board and with the 1964 Helsinki declaration and its later amendments or comparable ethical standards.

Informed Consent Informed consent was obtained from all individual participants included in the study.

Competing Interests The authors declare no competing interests.

Open Access This article is licensed under a Creative Commons Attribution 4.0 International License, which permits use, sharing, adaptation, distribution and reproduction in any medium or format, as long as you give appropriate credit to the original author(s) and the source, provide a link to the Creative Commons licence, and indicate if changes were made. The images or other third party material in this article are included in the article's Creative Commons licence, unless indicated otherwise in a credit line to the material. If material is not included in the article's Creative Commons licence and your intended use is not permitted by statutory regulation or exceeds the permitted use, you will need to obtain permission directly from the copyright holder. To view a copy of this licence, visit http://creativecommons.org/licenses/by/4.0/.

\section{References}

AAPT. (n.d.). Computational modeling in physics first with Bootstrap. Resource document. AAPT. https://aapt.org/K12/ComputationalModeling-in-Physics-First.cfm. Accessed 01 September 2021.

American Modeling Teachers Association. (n.d.) What is AMTA? https://www.modelinginstruction.org/. Accessed 01 September 2021.

Berlin, D. F. (1991). A bibliography of integrated science and mathematics teaching and learning literature. School science and mathematics association topics for teacher series (No. 6). Bowling Green, OH: School Science and Mathematics Association.

Berlin, D. F., \& Lee, H. (2003). A bibliography of integrated science and mathematics teaching and learning literature. Office of Educational Research and Improvement, U.S. Department of Education: Washington, DC.

Berlin, D. F., \& Lee, H. (2005). Integrating science and mathematics education: Historical analysis. School Science and Mathematics, 105(1), 15-24.

Bootstrap. (2021). Bootstrap. (n.d.). http://www.bootstrapworld.org Accessed 01 September 2021

Burawoy, M. (1998). The extended case method. Sociological Theory, 16(1), 4-33.

Caballero, M. D. (2011). Evaluating and extending a novel course reform of introductory mechanics. $\mathrm{PhD}$ thesis, Georgia Institute of Technology.

Caballero, M. D., Kohlmyer, M. A., \& Schatz, M. F. (2012). Implementing and assessing computational modeling in introductory mechanics. Physical Review Special Topics - Physics Education Research, 8(2), 020106-1-15.
Caballero, M. D., Burk, J. B., Aiken, J. M., Thoms, B. D., Douglas, S. S., Scanlon, E. M., \& Schatz, M. F. (2014). Integrating numerical computation into the modeling instruction curriculum. The Physics Teacher, 52(1), 38-42.

Chabay, R. W., \& Sherwood, B. A. (2008). Computational physics in the introductory calculus-based course. American Journal of Physics, 76(4/5), 307-313.

Chabay, R. W., \& Sherwood, B. A. (2015). Matter \& interactions. John Wiley \& Sons.

Chonacky, N., \& Winch, D. (2008). Integrating computation into the undergraduate curriculum: A vision and guidelines for future developments. American Journal of Physics, 76(4), 327.

Code.org. (n.d.). CODE. Resource document. https://code.org/.Code. org. Accessed 01 September 2021

Cook, D. M. (2008, 04). Computation in undergraduate physics: The Lawrence approach. American Journal of Physics, 76(4), 321-326.

CSforAll. (n.d.). Join the movement to bring computer science to ALL students. Resource document. https://www.csforall.org/.CSforAll. Accessed 01 Septmber 2021

CSTA. (2017). CSTA K-12 computer science standards. Resource document. CSTA. https://www.csteachers.org/general/custom. asp?page $=$ standards. Accessed 13 Oct 2020.

Czerniak, C., Weber JrSandmann, W. B. A., \& Ahern, J. (1999). A literature review of science and mathematics integration. School Science and Mathematics, 9(8), 421-430.

DiSessa, A. A. (2001). Changing Minds: Computers, Learning, and Literacy. The MIT Press.

Erickson, F. (1986). Qualitative methods in research on teaching. In M. C. Wittrock \& American Educational Research Association (Eds.), Handbook of Research on Teaching (3rd ed., pp. 119-161).

Esquembre, F. (2007). Integrating computer modeling into the curriculum. Presented at the 2007 AAPT Topical Conference: Computational Physics for Upper-Level Physics Programs, Davidson, NC.

Felleisen, M., Krishnamurthi, S., Findler, R. B., \& Flatt, M. (2001). How to design programs: An introduction to programming and computing. The MIT Press.

Glaser, B. (1965). The constant comparative method of qualitative analysis. Social Problems, 12(4), 445, 436.

Hestenes, D. (1987). Toward a modeling theory of physics instruction. American Journal of Physics, 55(5), 440-454.

Hestenes, D., Wells, M., \& Swackhamer, G. (1992). Force concept inventory. Physics Teacher, 30(3), 141-158.

Hurley, M. H. (2001). Reviewing integrated science and mathematics: The search for evidence and definitions from new perspectives. School Science and Mathematics, 101(5), 259-268.

Johnson-Laird, P. N. (1983). Mental models: Towards a cognitive science of language, inference, and consciousness. Cambridge University Press.

K-12 Computer Science Framework. (2017). Resource document. https://k12cs.org/. Accessed 13 Oct 2020.

Kapon, S., Laherto, A., \& Levrini, O. (2018). Disciplinary authenticity and personal relevance in school science. Science Education, 102, 1077-1106.

Kelley, T. R., Knowles, J. G., Holland, J. D., \& Han, J. (2020). Increasing high school teachers self-efficacy for integrated STEM instruction through collaborative community of practice. International Journal of STEM Education, 7(14), 1-13.

Langbeheim, E., Perl, D., \& Yerushalmi, E. (2020). Science teachers' attitudes towards computational modeling in the context of an inquiry-based learning module. Journal of Science Education and Technology. https://doi.org/10.1007/s10956-020-09855-3

Lunk, B. R. (2012). A framework for understanding physics students' computational modeling practices. Ph.D. thesis, North Carolina State University. 
McIntyre, D. H., Tate, J., \& Manogue, C. A. (2008). Integrating computational activities into the upper-level paradigms in physics curriculum at Oregon State University. American Journal of Physics, 76(4), 340-346.

Mueller, J., Wood, E., Willoughby, T., Ross, C., \& Specht, J. (2008). Identifying discriminating variables between teachers who fully integrate computers and teachers with limited integration. Computers \& Education, 51, 1523-1537.

NAE \& NRC: National Academy of Engineering \& National Research Council. (2014). STEM integration in K12 education: Status, prospects, and an agenda for research. Washington, DC: The National Academies Press.

NASEM: National Academies of Science, Engineering, and Medicine. (2010). Report of a workshop on the scope and nature of computational thinking. Washington, DC: National Academies Press, Washington, DC.

NASEM: National Academies of Sciences, Engineering, and Medicine. (2018). How people learn II: Learners, contexts, and cultures. Washington, DC: The National Academies Press. https://doi.org/ $10.17226 / 24783$

NGSS Lead States. (2013). Next generation science standards: For states, by states. The National Academies Press.

Niedderer, H., Schecker, H., \& Bethge, T. (1991). The role of computer-aided modelling in learning physics. Journal of Computer Assisted Learning, 7(2), 95.

NRC: National Research Council. (2000). How people learn: Brain, mind, experience, and school: expanded edition. Washington, DC: The National Academies Press. https://doi.org/10.17226/9853

NRC: National Research Council. (2011). A framework for K-12 science education. Washington, DC: National Academies Press.

NRC: National Research Council. (2012). Discipline-based education research: Understanding and improving learning in undergraduate science and engineering. Washington, DC: The National Academies Press. https://doi.org/10.17226/13362

NSF: National Science Foundation. (2019). STEM+C Computing K-12 Education $(S T E M+C)$. Resource document. NSF. https://www. nsf.gov/funding/pgm_summ.jsp?pims_id=505006. Accessed 13 Oct 2020.

Obsniuk, M. J., Irving, P., \& Caballero, M. D. (2015). A case study: Novel group interactions through introductory computational physics. In Physics Education Research Conference 2015, PER Conference, 239-242.

Orban, C. M., \& Teeling-Smith, R. M. (2020). Computational thinking in introductory physics. The Physics Teacher, 58(3), 247-251.

Pang, J., \& Good, R. (2000). A review of the integration of science and mathematics: Implications for further research. Science Science and Mathematics, 100(2), 73-82.

PICUP: Partnership for Integration of Computation into Undergraduate Physics. (n.d.). American association of physics teachers. https:// www.compadre.org/PICUP

Piaget, J. (1964). Cognitive development in children: Development and learning. Journal of Research in Science Teaching, 2, 176-186.

Sherin, B. L., diSessa, A. A., \& Hammer, D. (1993). Dynaturtle revisited: Learning physics through collaborative design of a computer model. Interactive Learning Environments, 3(2), 91-118.
Sherin, B. L. (2001). A comparison of programming languages and algebraic notation as expressive languages for physics. International Journal of Computers for Mathematical Learning, 6(1), $1-61$.

Spencer, R. L. (2005). Teaching computational physics as a laboratory sequence. American Journal of Physics, 73(2), 151-153.

Stubbs, E. A., \& Myers, B. E. (2016). Part of what we do: Teacher perceptions of STEM integration. Journal of Agricultural Education, 57(3), 87-100.

Timberlake, T., \& Hasbun, J. (2008). Computation in classical mechanics. American Journal of Physics, 76(4/5), 334-339.

Wang, H. H., Moore, T. J., Roehrig, G. H., \& Park, M. S. (2011). STEM integration: Teacher perceptions and practice, Journal of Pre-College Engineering Education Research (J-PEER), 1(2), article 2.

Watkins, J., Coffey, J. E., Redish, E. F., \& Cooke, T. J. (2012). Disciplinary authenticity: Enriching the reforms of introductory physics courses for life-science students. Physical Review Special Topics - Physics Education Research, 8, Article 010112.

Weatherford, S. A. (2011). Student use of physics to make sense of incomplete but functional VPython programs in a lab setting. $\mathrm{PhD}$ thesis, North Carolina State University.

Weintrop, D., Beheshti, E., Horn, M., Orton, K., Jona, K., Trouille, L., \& Wilensky, U. (2016). Defining computational thinking for mathematics and science classrooms. Journal of Science Education and Technology, 25(1), 127147.

Wells, M., Hestenes, D., \& Swackhamer, G. (1995). A modeling method for high school physics instruction. The Physics Teacher, 63(7), 606-619.

White, S., \& Tesfaye, L. (2011). Female students in high school physics: Results from the 2008-09 nationwide survey of high school physics teachers. American Institute of Physics. https://www.aip. org/statistics/reports/female-students-high-school-physics

White, S., \& Tesfaye, L. (2014). High school physics courses and enrollments: A 2012-13 nationwide survey of high school physics teachers. American Institute of Physics. https://www.aip.org/ statistics/reports/high-school-physics-courses-enrollments-0

White, S., \& Tyler, J. (2015). Underrepresented minorities in high school physics: Results from the 2012-13 nationwide survey of high school physics teachers. American Institute of Physics. https:// www.aip.org/statistics/reports/underrepresented-minorities-highschool-physics

Wing, J. (2006). Computational thinking. Communications of the ACM, 49(3), 33-35.

Yin, R. K. (2009). Case Study Research, 4th Ed. Sage: Thousand Oaks, CA.

Sherer, D., Dubois, P., \& Sherwood, B. (2000). VPython: 3D interactive scientific graphics for students. Computing in Science \& Engineering, 2(5), 56-62.

Publisher's Note Springer Nature remains neutral with regard to jurisdictional claims in published maps and institutional affiliations. 